Оригинальная статья/Original article

УДК 664.71.013

DOI: http://doi.org/10.20914/2310-1202-2017-1-62-67

Разработка линии подготовки зерна сафлора к переработке

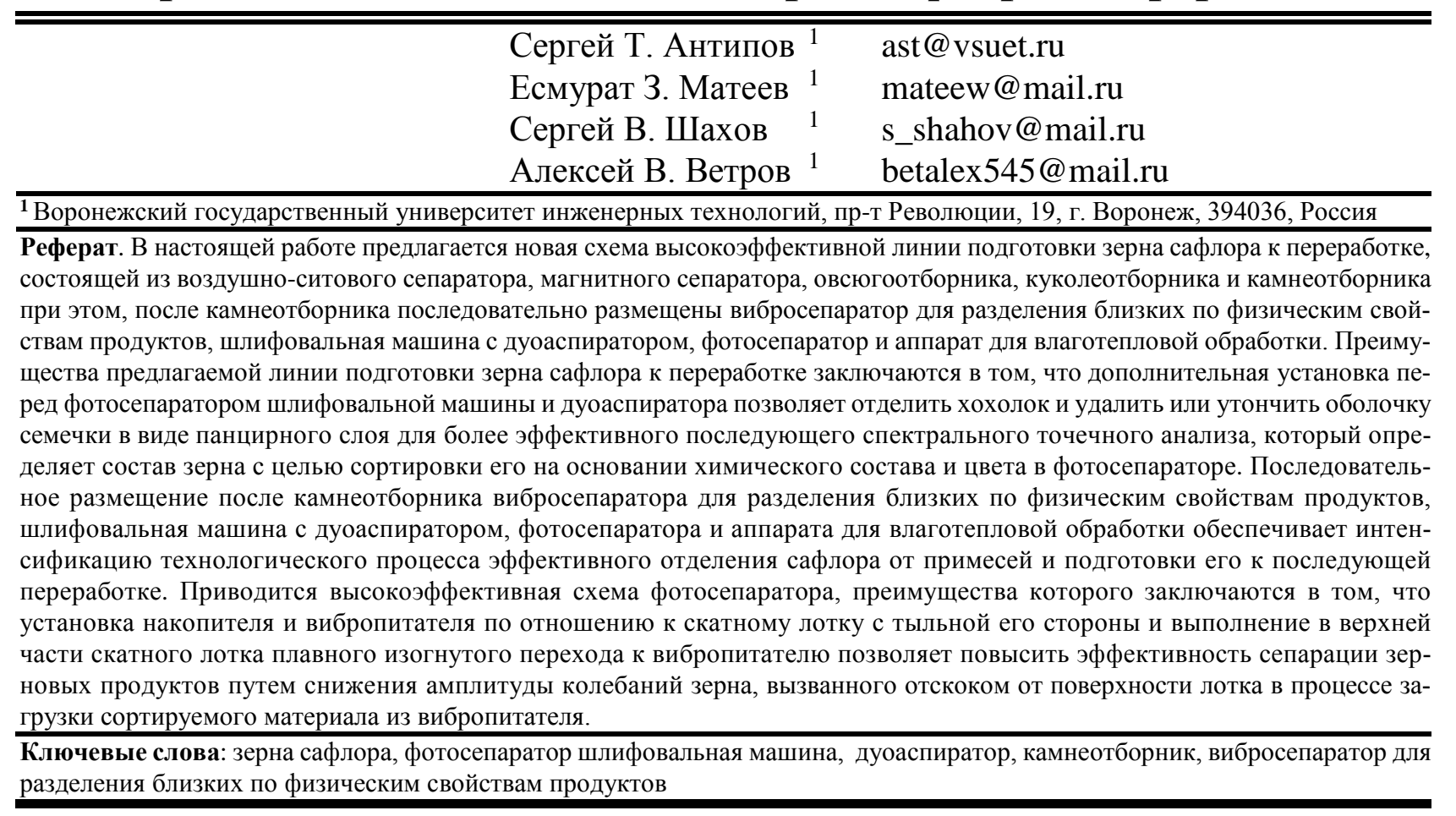

\title{
Investigation of wettability to evaluate the morphology and surface tension wood filler
}

\begin{tabular}{|c|c|c|}
\hline $\begin{array}{l}\text { Sergey T. Antipov } \\
\text { Yesmurat Z. Mateyev } \\
\text { Sergey V. Shahov } \\
\text { Alexey V. Vetrov }\end{array}$ & & ast@vsuet.ru \\
\hline \multicolumn{3}{|c|}{$\begin{array}{l}\text { Summary.In this paper, we propose a new scheme of a highly efficient line for preparing safflower grains for processing consisting } \\
\text { of an air-sieve separator, a magnetic separator, an ovary, a puppet, and a stone picker. The new after vortex separator is a vibroseparator } \\
\text { for separating the products close in physical properties, grinding Machine with a duo-aspirator, a photoseparator and a device for } \\
\text { moisture-thermal treatment. Advantages of the proposed line for preparation of safflower grain for processing are that an additional } \\
\text { plant in front of the photocarerator of the grinding machine and duo-espirator allows the crest to separate and remove or refine the } \\
\text { shell of the seed in the form of a shell layer for more efficient subsequent spectral point analysis, which determines the grain compo- } \\
\text { sition for the purpose of sorting it On the basis of chemical composition and color in the photo separator, and sequential placement } \\
\text { after the stone separator of a vibro separator for separation of products close in physical properties, a grinding machine with a duo- } \\
\text { aspirator, a photoseparator and a device for moisture-thermal treatment, provides an intensification of the technological process of } \\
\text { efficient separation of safflower from impurities and its preparation for further processing and Due to the rational layout of equip- } \\
\text { ment.A highly efficient photocell separator is also provided, the advantages of which are that the installation of a storage and vibrating } \\
\text { feeder in relation to the slanting tray from the back side and the execution of a smooth curved transition to the vibrating feeder in the } \\
\text { upper part of the pitcher allows improving the separation of grain products by reducing the amplitude of grain oscillations, Caused by } \\
\text { a rebound from the surface of the tray during the loading of the sorted material from the vibrating feeder. }\end{array}$} \\
\hline
\end{tabular}

Keywords: grains of safflower, photo separator grinding machine, duoespirator, stone separator, vibro separator for separation of close in physical properties products

\section{Для цитирования}

Антипов С. Т., Матеев Е. З., Шахов С. В., Ветров А. В. Разработка линии подготовки зерна сафлора к переработке // Вестник ВГУИТ. 2017. T. 79. № 1. С. 62-67. doi:10.20914/2310-1202-2017-1-62-67
For citation

Antipov S. T., Mateyev Ye. Z., Shahov S. V., Vetrov A. V. Investigation of wettability to evaluate the morphology and surface tension wood filler. Vestnik VGUIT [Proceedings of VSUET]. 2017. Vol. 79. no. 1. pp. 62-67. (in Russian). doi:10.20914/2310-1202-2017-1-62-67 


\section{Введение}

Важнейшей задачей для сельского хозяйства и перерабатывающей промышленности является совершенствование процесса очистки зерна сафлора, обусловленное требованиями, предъявляемыми к качеству масличного сырья [1-8]. Лимитирующим моментом этого процесса является выделение семян трудноотделимых примесей, незначительно отличающихся от зерен сафлора. Из примесей в зерновой массе сафлора к наиболее трудноотделимым относятся семена прицепника широколистного, которые по физико-механическим свойствам близки к зерну сафлора [9-13].

Недостатками известных линий переработки семян масличных культур являются ограниченные функциональные возможности линии, которые не позволяют обеспечить эффективное отделение зерна сафлора от примесей и подготовить к дальнейшей переработке по извлечению сафлорового масла.

Поэтому предлагается новая схема высокоэффективной линии подготовки зерна сафлора к переработке, обеспечивающая интенсификацию технологического процесса отделения зерна сафлора от примесей и подготовки к дальнейшей переработке по извлечению сафлорового масла за счет рациональной компоновки оборудования.

Технологическая схема линии подготовки зерна сафлора к переработке (рисунок 1) состоит из ковшового элеватора (нории) 1 , приемного бункера 2, воздушно-ситового сепаратора 3 , предназначенного для очистки зерна сафлора от легких, мелких, крупных примесей, магнитного сепаратора 4, осуществляющего удаление ферромагнитных частиц, овсюгоотборника и куколеотборника 5, камнеотделителя 6 для выделения минеральных примесей (галька, песок и т. д.) и щуплого зерна сафлора, вибросепаратора 7 для разделения близких по физическим свойствам продуктов (например, для выделения прицепника широколистного), шлифовальной машины 8 , предназначенного для очистки поверхности зерна сафлора, удаления хохолков и утончения панцирной оболочки зерна, дуоаспиратора 9, фотоэлектронного сепаратора 10, предназначенного для выделения примесей, отличающихся от зерна пшеницы по цвету, аппарат для влаготепловой обработки 11.

Технологическая схема линии подготовки зерна сафлора к переработке работает следующим образом.
Исходная зерновая смесь поступает в норию 1 и транспортируется в приёмный бункер 2. При этом исходная зерновая смесь состоит из сафлора $-90 \%$ (рисунок 2); грубого сора $-2 \%$; семян вьюнка - $1 \%$ (рисунок 3), семян прицепника широколистного - 4\% (рисунок 4), и легких примесей (не показаны). В разных партиях зерна содержится до 9-11\% прицепника широколистного. Из приёмного бункера 2 зерновая масса равномерно подаётся в воздушно-ситовой сепаратор 3. Воздушно-ситовой сепаратор 3 очищает зерно от крупных I, мелких II и лёгких III примесей.

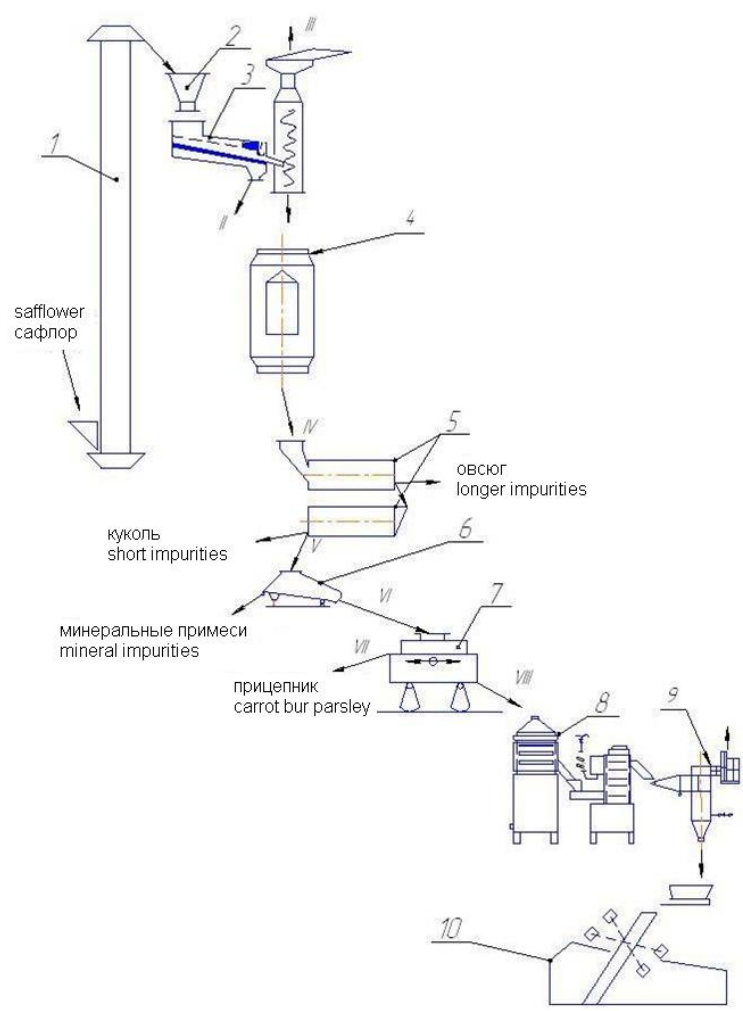

Рисунок 1. Принципиальная технологическая схема линии подготовки зерна сафлора к переработке

Figure 1. The basic technological scheme of the line for preparation of safflower grain for processing

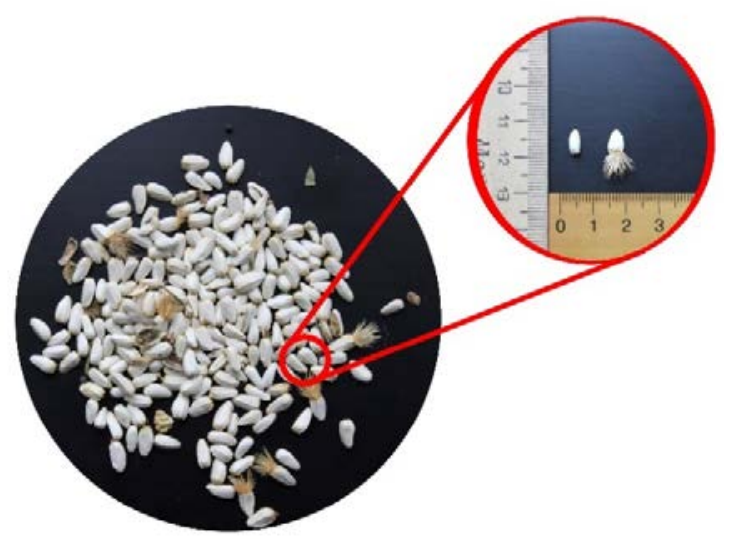

Рисунок 2. Зерно сафлора до и после удаления хохолка

Figure 2. Grain of safflower before and after removal of tuft 

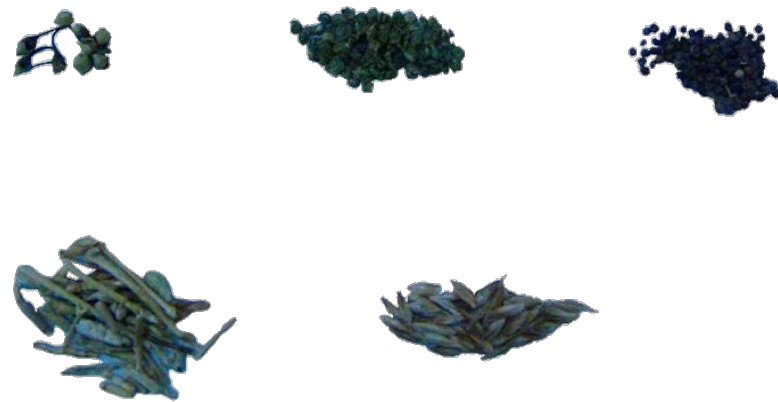

Рисунок 3. Крупные и мелкие сорные примеси

Figure 3. Large and small weeds

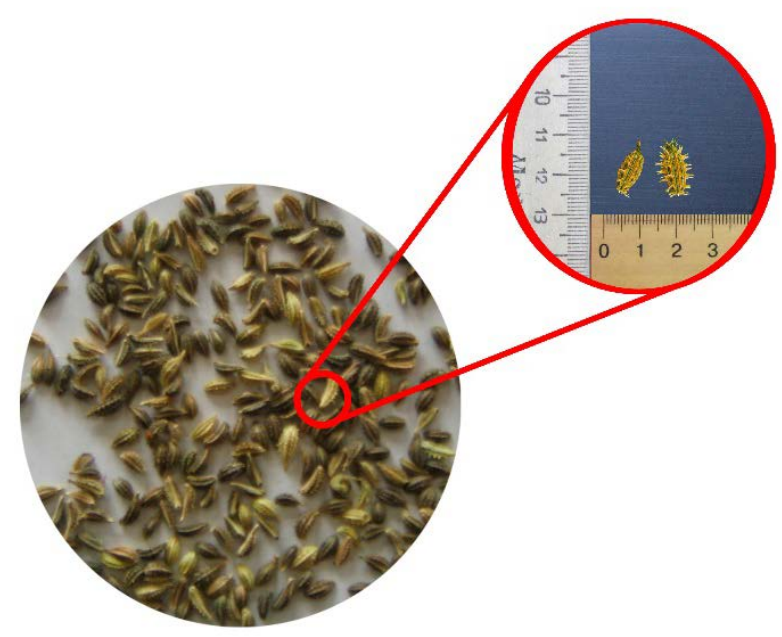

Рисунок 4. Прицепник широколистный

Figure 4. Broad-leafhook-on

Однако, разделением сафлора и вьюнка просеиванием на ситах возможно очистка до 98-99\%, так как по основному параметру ширине, на вариационных кривых (рисунок 5) наблюдается небольшое наложение, которое при разделении на ситах с продолговатыми отверстиями $2 \times 20$ мм не влияет на эффективность очистки. Это объясняется тем, что толщиной в пределе до 2 мм характеризуются щуплые, недозрелые зёрна сафлора и представляют собой зерновую примесь.

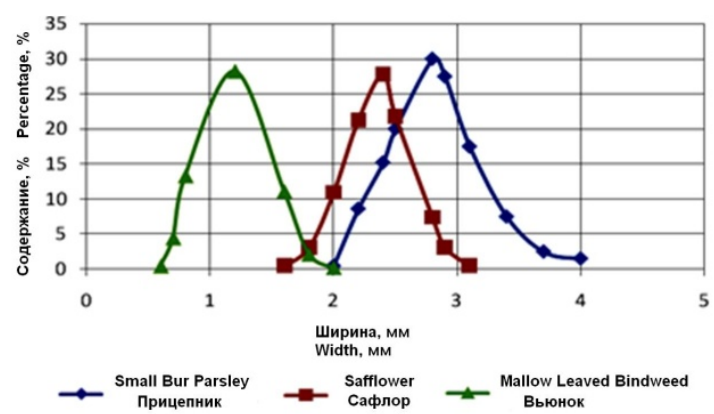

Рисунок 5. Вариационные кривые распределения семян сафлора и его примесей по ширине

Figure 5. Variation curves for the distribution of seeds of safflower and its impurities in width
Зерновая смесь IV с семенами прицепника широколистного, минеральными и другими примесями поступает самотёком в промежуточный бункер. Из промежуточного бункера зерновая масса сафлора подаётся в магнитный сепаратор 4, где она отделяется от ферромагнитных примесей.

Зерновая масса направляется в триеровсюгоотборник 5, где короткие зерна и примеси длиной меньше диаметра ячеек захватываются ими и направляются вверх. Над лотком семена под действием силы тяжести выпадают из ячеек и направляются в шнек, по которому они выводятся по лотку из цилиндра. Длинные семена, частично попадая в ячейки, не удерживаются в них и выпадают, не доходя до лотка. Далее они перемещаются вдоль оси цилиндра и идут сходом по ячеистой поверхности. Так из зерновой смеси выделяются зерновки овсюга.

Затем зерновая смесь попадает в триеркуколеотборник 5. Там она проходит очистку от коротких примесей - куколя. Семена куколя лучше заполняют ячейки и свободно выпадают из них над лотком тогда, когда цилиндр будет вращаться с определенной скоростью, а остальные частицы перемещаются сходом вдоль оси цилиндра.

Далее зерновая смесь V, очищенная от крупных, мелких, лёгких, длинных (овсюг) и коротких (куколь) примесей поступает в камнеотделительную машину 6.

В камнеотделительной машине 6 происходит выделение минеральных частиц (камней) из зерновой смеси. После сепарирования в камнеотделительной машине зерновая смесь VI поступает в промежуточный бункер (на схеме не показано).

Из промежуточного бункера зерновая смесь VI подаётся в приёмное устройство вибросепаратора 7 для выделения близких по физическим свойствам продуктов, например, прицепник широколистный. Использование вибросепаратора 7 в процессе отделения сафлора от прицепника широколистного связано с тем, что геометрические размеры зерен сафлора и семян прицепника широколистного, отличаются незначительно, поэтому полное разделение их по геометрическим размерам не обеспечивается. В вибросепараторе 7 , зерновая смесь из приёмного устройства частицы попадают в каналы сепарирования, образованные зигзагообразными отражателями, закреплёнными на сортировальном столе сепаратора для выделения прицепника широколистного. В каналах сепарирования, образованных зигзагообразными отражателями в процессе виброударного самосортирования, разделяются сафлор VIII и прицепник широколистный VI.

Зерновая масса направляется на шлифовальную машину 8 , где происходит очистка поверхности зерна, удаление хохолка, утончение панцирной оболочки, а по возможности и полное ее удаление. Из шлифовальной машины 8 зерновая 
масса поступает в дуоаспиратор 9, а отрубинистые частицы легкой фракции, выделенные аспирационным устройством, выводятся из производства.

Из дуоаспиратора 9 зерновая масса поступает в фотоэлектронный сепаратор 10.

Предварительная подготовка с использованием шлифовальной машины 8 перед фотоэлектронным сепаратором 10 позволяет в последующем эффективно проводить спектральный точечный анализ зерна с целью сортировки его на основании химического состава и цвета.

Выделенные зерна сафлора, затем подаются в аппарат для влаготепловой обработки.

Одним из ключевых единиц оборудования данной линии является фотоэлектронный сепаратор 10. Однако при его работе выявлено, что в процессе загрузки сортируемого материала из вибропитателя наблюдается высокая амплитуда колебаний зерна, вызванных отскоком от поверхности лотка и это снижает эффективность сепарации зерновых продуктов. Поэтому предложена конструкция фотоэлектронного сепаратора, устраняющего этот недостаток.

Предложенный фотоэлектронный сепаратор 10 содержит устройство транспортировки сортируемого материала, состоящее из накопителя 1 и вибропитателя 2 со скатным лотком 3 (рисунок 6). При этом накопитель 1 и вибропитатель 2 установлены по отношению к скатному лотку 3 с тыльной его стороны. В верхней части скатный лоток 3 имеет плавный изогнутый переход к вибропитателю 2.

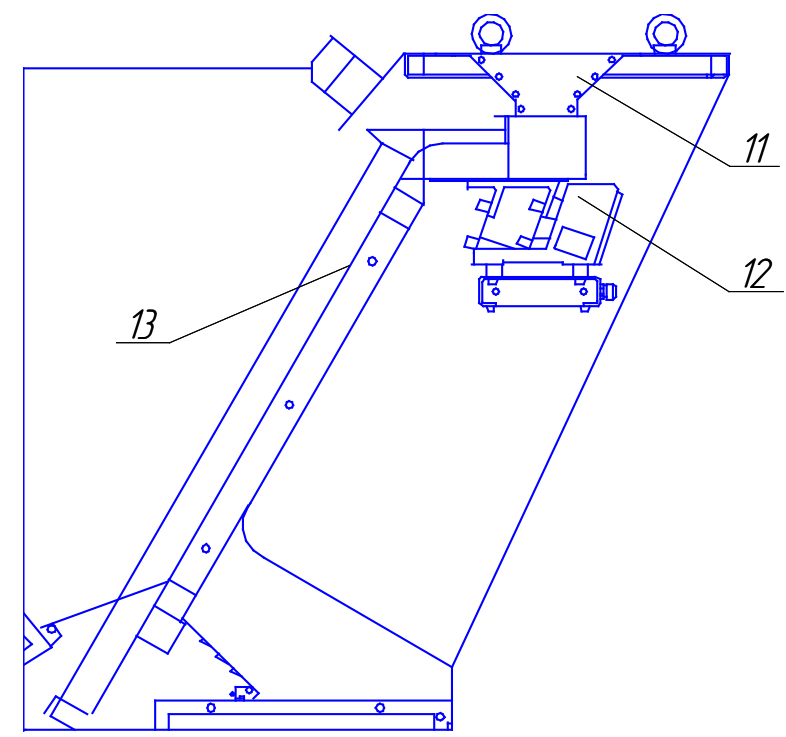

Рисунок 6. Общий вид фотоэлектронного сепаратора

Figure 6. General view of the photoelectric separator

Фотоэлектронный сепаратор 10 (рисунок 7) также содержит устройство лазерного освещения сортируемого материала, состоящее из оптического волокна 14, вход которого через фокусирующую оптику 15 и поворотные призмы 16 связан с оптическими выходами одного или нескольких лазеров 17, а выход оптического волокна 14 связан с фокусирующей и цилиндрической оптикой 18, 19 устройства развертки лазерного пучка 20, а также устройство считывания и обработки изображения 21, устройство для удаления дефектных материалов 22.

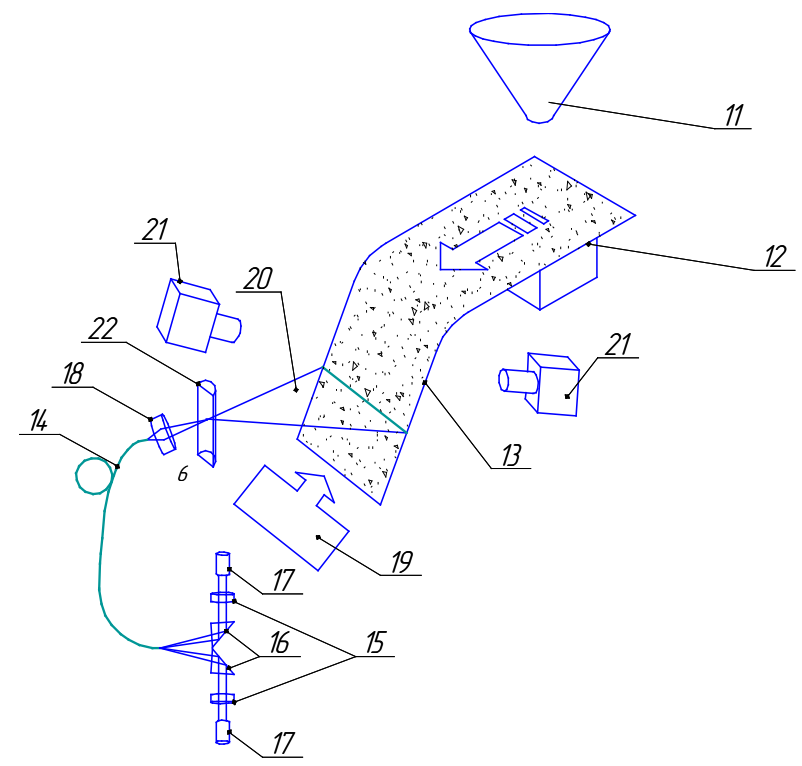

Рисунок 7. Принципиальная схема устройства и принципа действия фотоэлектронного сепаратора

Figure 7. Schematic diagram of the device and the principle of the action of the photoelectric separator

Фотоэлектронный сепаратор 10 может содержать два и более устройства считывания и обработки изображений 21, ориентированных как на считывание отраженного и прошедшего через материал лазерного освещения, так и на считывание в разных спектральных диапазонах.

Работа фотоэлектронного сепаратора осуществляется следующим образом. Устройство транспортировки сортируемого материала из накопителя 11 с помощью вибропитателя 12 и скатного лотка 13 подает продукт в зону лазерного освещения, и благодаря скруглению скатного лотка 13 сортируемый материал перемещается без отскока от него.

Излучение одного или нескольких лазеров 17 фокусирующей оптикой 15 проецируется на входном торце оптического волокна 14. Излучение выходного торца оптического волокна 14 фокусирующей и цилиндрической оптикой 18 , 19 проецируется на плоскость зоны регистрации изображения в виде светового пучка 20. Цилиндрическая оптика 19 устройства развертки лазерного пучка 20 рассчитывается так, чтобы освещаемая область совпала с зоной регистрации изображения устройством 21, содержащим линейный видеодатчик. Неравномерность интенсивности в зоне освещения может быть скомпенсирована на этапе формирования 


\section{Becmник BTYYHTI/Proceedings of VSVET, TIT. 79, № 1, 2017}

и обработки видеосигнала в устройстве 21. Устройство считывания и обработки изображения 21 за время, не превышающее времени прохождения продукта от зоны регистрации изображения до устройства удаления дефектных материалов 9, принимает решение об удалении некондиционного продукта. Устройство 21 в расчетное время формирует адрес пространственного положения удаляемого объекта и активизирует работу устройства 22 удаления дефектных материалов. Поворотные призмы 16 позволяют ограничить угловой спектр вводимого в оптический волновод излучения и упростить задачу пространственного размещения лазеров 17 и оптических элементов формирования развертки лазерного пучка 20.

Падающий или движущийся поток продукта ограничен по ширине апертурой регистрируемого изображения и по лучу зрения глубиной резкости объектива устройства считывания 21.

\section{Выводы}

Преимущества предлагаемой линии подготовки зерна сафлора к переработке заключаются в том, что дополнительная установка перед фотосепаратором шлифовальной машины и дуоаспиратора позволяет отделить хохолок

\section{ЛИТЕРАТУРА}

1 Имантаев 3. 3., Матеев Е. 3., Усманов А. А. Сафлор - ценная масличная культура // Вестник $\mathrm{c} / \mathrm{x}$ ой науки Казахстана. 2011. № 10. С. 28-30.

2 Кадирбаев М.К., Еркебаев М.Ж., Некрасов А.В., Матеев Е. З., Садвокасова Д. С., Шахов С. В. Выбор и обоснование сита для очистки сафлора от крупных примесей // Вестник Алматинского гуманитарнотехнического университета. 2013. № 2. С. 12-14.

3 Еркебаев М.Ж., Кадирбаев М.К., Матеев Е.З., Шахов С. В. Физико-механические свойства семян сафлора // Финансы. Экономика. Стратегия. Серия «Инновационная экономика: человеческое измерение». 2013. № 11. С. 17-19.

4 Кадирбаев М. К., Матеев Е. З., Шахов С. В., Юрова И. С. Определение состава зерновой смеси софлора и сопутствующих примесей // Экономика. Инновации. Управление качеством. 2014. № 4. С. 72-72.

5 Пат. РФ № 2558836. Вибрационный сепаратор для разделения близких по физическим свойствам частиц / Шахов С. В., Матеев Е. З., Ветров А. В., Субботина А. Н. Опубл. 10.08.2015. Бюл. № 22.

6 Инновационный патент РК на изобретение № 30536. Вибрационный сепаратор для разделения близких по физическим свойствам частиц / Матеев Е. 3., Кадирбаев М. К., Шахов С. В., Некрасов А. В., Жумабекова 3. А., Шалгинбаев Д. Б. Опубл. 16.11.2015. Бюл. № 11.4 c.

7 Costin A., Syster T., Cramer R. Sorting Machine with Color Light to Digital Convertor (CLDC). - 2014.

8 Zhong W. et al. The research of color sorting algorithm based on gray level co-occurrence matrix // Measurement, Information and Control (ICMIC), 2013 International Conference on. IEEE, 2013. T. 2. C. 926-930. и удалить или утончить оболочку семечки в виде панцирного слоя для более эффективного последующего спектрального точечного анализа, который определяет состав зерна с целью сортировки его на основании химического состава и цвета в фотосепараторе. Последовательное размещение после камнеотборника вибросепаратора для разделения близких по физическим свойствам продуктов, шлифовальная машина с дуоаспиратором, фотосепаратора обеспечивает интенсификацию технологического процесса эффективного отделения сафлора от примесей и подготовки его к последующей переработке и за счет рациональной компоновки оборудования.

Преимущества фотоэлектронного сепаратора заключаются в том, что установка накопителя и вибропитателя по отношению к скатному лотку с тыльной его стороны и выполнение в верхней части скатного лотка плавного изогнутого перехода к вибропитателю позволяет повысить эффективность сепарации зерновых продуктов путем снижения амплитуды колебаний зерна, вызванного отскоком от поверхности лотка в процессе загрузки сортируемого материала из вибропитателя.

9 Xiao Y., Wang H., Shao X. 2D numerical modeling of grain-sorting processes and grain size distributions // Journal of Hydro-environment Research. 2014. T. 8. №. 4. C. 452-458.

10 Kroulík M. et al. Pneumatic conveying characteristics of seeds in a vertical ascending airstream // Research in Agricultural Engineering. 2016. T. 62. №. 2. C. 56-63.

11 Nagy E. K., Korzenszky P., Sembery P. The role of color sorting machine in reducing food safety risks // Potravinarstvo. 2016. T. 10. №. 1.

12 Василенко В.Н., Фролова Л.Н., Михайлова Н.А., Дерканосова А.А., Таркаева Д.А., Русина К.Ю. Оценка термодинамической эффективности линии производства растительных масел с предварительной экструзионной обработкой сырья // Вестник Международной академии холода. 2016. № 3. С. 37-42.

\section{REFERENCES}

1 Imantaev Z. Z., Mateev E. Z., Usmanov A. A. Safflower is a valuable oilseed crop. Vestnik $s / k h-o i$ nauki Kazakhstana [Proceedings of Kazakhstan]. 2011. no. 10. pp. 28-30. (in Russian).

2 Kadirbaev M. K., Erkebaev M. Zh., Nekrasov A. V., Mateev E. Z., Sadvokasova D. S., Shakhov S. V. Selection and justification of a sieve for the purification of safflower impurities from large. Vestnik Almatinskogo gumanitarno-tekhnicheskogo universiteta [Proceedings of Almaty humanitarian-technical University]. 2013. no. 2. pp. 12-14. (in Russian).

3 Erkebaev M. Zh., Kadirbaev M. K., Mateev E. Z., Shakhov S. V. Physico-mechanical properties of safflower seed. Finansy. Ekonomika. Strategiya. Seriya "Innovatsionnaya ekonomika: chelovecheskoe izmerenie" [Finance. Economy. Strategy. Series "Innovative economy: the human dimension”]. 2013. no. 11. pp. 17-19. (in Russian). 
4 Kadirbaev M. K., Mateev E. Z., Shakhov S. V., Yurova I. S. The composition of the grain mixture in zoflora and related impurities. Ekonomika. Innovatsii. Upravlenie kachestvom [Economy. Innovation. The management of quality]. 2014. no. 4. pp. 72-72. (in Russian).

5 Shakhov S. V., Mateev E. Z., Vetrov A. V., Subbotina A. N. Vibratsionnyi separator dlya razdeleniya blizkikh po fizicheskim svoistvam chastits [A vibratory separator for separating loved ones on the physical properties of particles]. Patent RF, no. 2558836. Publ. 10.08.2015.

6 Mateev E.Z., Kadirbaev M.K., Shakhov S.V., Nekrasov A.V., Zhumabekova Z.A., Shalginbaev D.B. Vibratsionnyi separator dlya razdeleniya blizkikh po fizicheskim svoistvam chastits [Vibration separator for separation of particles close in physical properties]. Innovative patent of the Republic of Kazakhstan no. 30536. 2015.

7 Costin A., Syster T., Cramer R. Sorting Machine with Color Light to Digital Convertor (CLDC). 2014.

\section{СВЕДЕНИЯ ОБ АВТОРАХ}

Сергей Т. Антипов д.т.н., профессор, зав. кафедрой, кафедра машин и аппаратов пищевых производств, Воронежский государственный университет инженерных технологий, пр-т Революции, 19, г. Воронеж, 394036 , Россия, ast@vsuet.ru

Есмурат 3. Матеев к .т. н., докторант, кафедра машин и аппаратов пищевых производств, Воронежский государственный университет инженерных технологий, пр-т Революции, 19, г. Воронеж, 394036, Россия, mateew@mail.ru Сергей В. Шаховд. т. н., профессор,кафедра машин и аппаратов пищевых производств,Воронежский государственный университет инженерных технологий,пр-т Революции, 19, г. Воронеж, 394036, Россия, s_shahov@mail.ru Алексей В. Ветров аспирант, кафедра машин и аппаратов пищевых производств, Воронежский государственный университет инженерных технологий, пр-т Революции, 19, г. Воронеж, 394036, Россия, betalex545@mail.ru

\section{КРИТЕРИЙ АВТОРСТВА}

Сергей Т. Антипов консультация в ходе исследования Есмурат 3. Матеев обзор литературных источников по исследуемой проблеме

Сергей В. Шахов написал рукопись, корректировал её до подачи в редакцию

Алексей В. Ветров несёт ответственность за плагиат

\section{КОНФЛИКТ ИНТЕРЕСОВ}

Авторы заявляют об отсутствии конфликта интересов. ПОСТУПИЛА 08.01.2017

ПРИНЯТА В ПЕЧАТЬ 01.02.2017
8 Zhong W. et al. The research of color sorting algorithm based on gray level co-occurrence matrix. Measurement, Information and Control (ICMIC), 2013 International Conference on. IEEE, 2013. vol. 2. pp. 926-930.

9 Xiao Y., Wang H., Shao X. 2D numerical modeling of grain-sorting processes and grain size distributions. Journal of Hydro-environment Research. 2014. vol. 8. no. 4. pp. 452-458.

10 Kroulík M. et al. Pneumatic conveying characteristics of seeds in a vertical ascending airstream. Research in Agricultural Engineering. 2016. vol. 62. no. 2. pp. 56-63.

11 Nagy E. K., Korzenszky P., Sembery P. The role of color sorting machine in reducing food safety risks. Potravinarstvo. 2016. vol. 10. no. 1.

12 Vasilenko V.N., Frolova L.N., Mikhailova N.A., Derkanosova A.A., Tarkaeva D.A., Rusina K.Yu. Estimation of the thermodynamic efficiency of the production line of vegetable oils with pre-extrusion treatment of raw materials Vestnik Mezhdunarodnoi akademii kholoda [Bulletin of the International academy of refrigeration] 2016, no. 3, pp. 37-42. (in Russian)

\section{INFORMATION ABOUT AUTHORS}

Sergey T. Antipov doctor of technical sciences, head of department , machines and apparatus of food production department, Voronezh state university of engineering technologies, Revolution Av., 19 Voronezh, 394036, Russia, ast@vsuet.ru

Yesmurat Z. Mateyev candidate of technical sciences, doctoral, machines and apparatus of food production department, Voronezh state university of engineering technologies, Revolution Av., 19 Voronezh, 394036, Russia, mateew@mail.ru

Sergey V. Shahovdoctor of technical sciences, professor,machines and apparatus of food production department, Voronezh state university of engineering technologies,Revolution Av., 19 Voronezh, 394036, Russia, s_shahov@mail.ru

Alexey V. Vetrov graduate student, machines and apparatus of food production department, Voronezh state university of engineering technologies, Revolution Av., 19 Voronezh, 394036, Russia, betalex545@mail.ru

\section{CONTRIBUTION}

Sergey T. Antipov consultation during the study

Yesmurat Z. Mateyev review of the literature on an investigated problem

Sergey V. Shahov wrote the manuscript, correct it before filing in editing

Alexey V. Vetrov is responsible for plagiarism

CONFLICT OF INTEREST

The authors declare no conflict of interest.

RECEIVED 1.8.2017

ACCEPTED 2.1.2017 